\title{
Introduction and approval of menstrual regulation with medication in Bangladesh: A stakeholder analysis
}

Fauzia Akhter Huda

Sadia Afrin

Bidhan Krishna Sarker

Hassan Rushekh Mahmood

Anadil Alam

Follow this and additional works at: https://knowledgecommons.popcouncil.org/departments_sbsr-rh

Part of the Demography, Population, and Ecology Commons, Family, Life Course, and Society Commons, International Public Health Commons, Obstetrics and Gynecology Commons, and the Women's Health Commons How does access to this work benefit you? Let us know!

\section{Recommended Citation}

Akhter Huda, Fauzia, Sadia Afrin, Bidhan Krishna Sarker, Hassan Rushekh Mahmood, and Anadil Alam. 2017. "Introduction and approval of menstrual regulation with medication in Bangladesh: A stakeholder analysis," STEP UP Research Report. Dhaka: icddr,b. 


\section{STEPTUP}

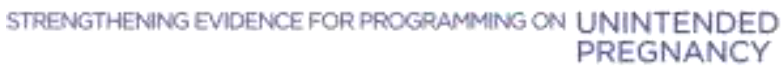

BANGLADESH

RESEARCH REPORT

March 2017

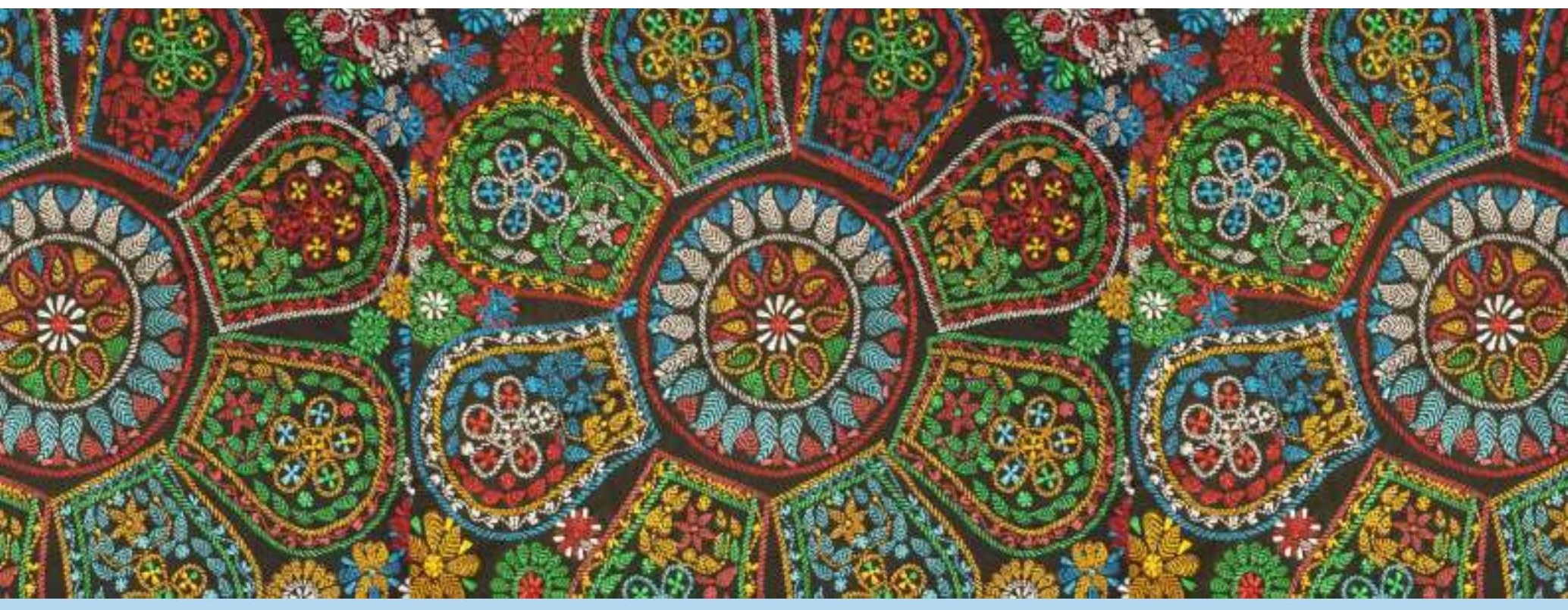

\section{Introduction and Approval of}

Menstrual Regulation with Medication in Bangladesh: A Stakeholder Analysis

FAUZIA AKHTER HUDA, SADIA AFRIN, BIDHAN KRISHNA SARKER, HASSAN RUSHEKH MAHMOOD, AND ANADIL ALAM 


\section{Introduction and Approval of Menstrual Regulation with Medication in Bangladesh: A Stakeholder Analysis}

FAUZIA AKHTER HUDA, SADIA AFRIN, BIDHAN KRISHNA SARKER, HASSAN RUSHEKH MAHMOOD, AND ANADIL ALAM

Maternal and Child Health Division (MCHD) icddr,b, Dhaka, Bangladesh

STEP UP RESEARCH REPORT

MARCH 2017

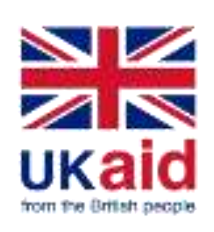


The STEP UP (Strengthening Evidence for Programming on Unintended Pregnancy) Research Programme Consortium generates policy-relevant research to promote an evidence-based approach for improving access to family planning and safe abortion. STEP UP focuses its activities in five countries: Bangladesh, Ghana, India, Kenya and Senegal. STEP UP is coordinated by the Population Council in partnership with the African Population and Health Research Center; icddr,b; the London School of Hygiene and Tropical Medicine; and Marie Stopes International. STEP UP is funded by UKaid from the UK Government. www.stepup.popcouncil.org

\section{(6) icddr,b}

Dedicated to saving lives, icddr,b is an international public health research organisation located in Bangladesh. Through the generation of knowledge and translation of research into treatment, training, and policy advocacy, icddr,b addresses some of the most critical health concerns facing the world today. www.icddrb.org

\section{POPUlation COUNCIL \\ Ideas. Evidence. Impact.}

The Population Council confronts critical health and development issues-from stopping the spread of HIV to improving reproductive health and ensuring that young people lead full and productive lives. Through biomedical, social science, and public health research in 50 countries, we work with our partners to deliver solutions that lead to more effective policies, programs, and technologies that improve lives around the world. Established in 1952 and headquartered in New York, the Council is a nongovernmental, nonprofit organization governed by an international board of trustees. www.popcouncil.org

Suggested citation: Huda FA; Afrin S; Sarker BK; Mahmood HR; and Alam A. 2017. "Introduction and Approval of Menstrual Regulation with Medication in Bangladesh: A Stakeholder Analysis" STEP UP Research Report. Dhaka: icddr,b.

\section{(C) 2017 icddr,b.}

Please address any inquiries about STEP UP to the RPC co-directors:

Harriet Birungi, hbirungi@popcouncil.org

Esther Lwanga, elwanga@popocouncil.org

Funded by

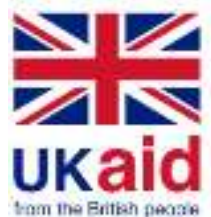


TABLE OF CONTENTS

ACKNOWLEDGMENTS.

LIST OF

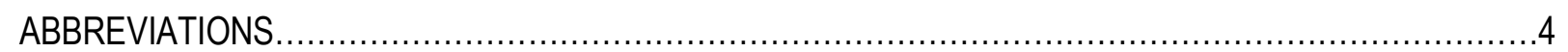

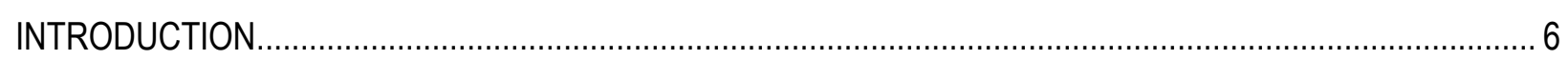

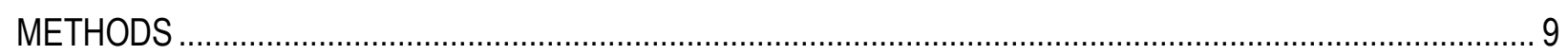

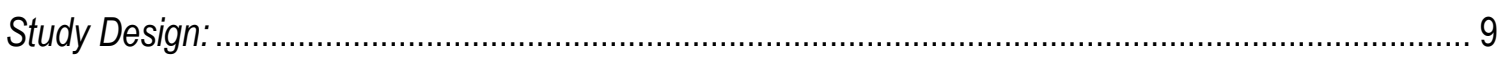

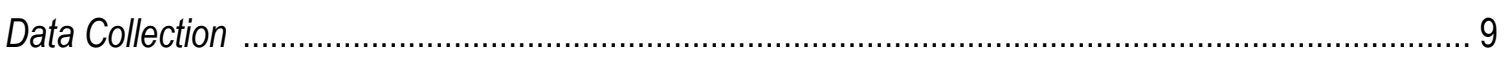

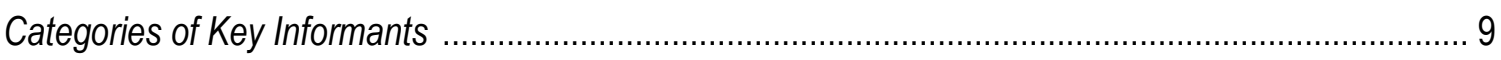

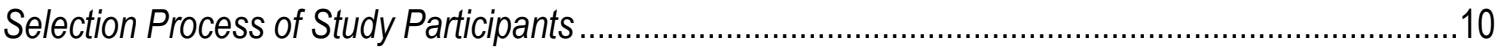

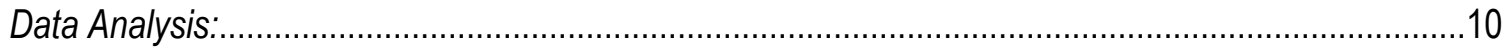

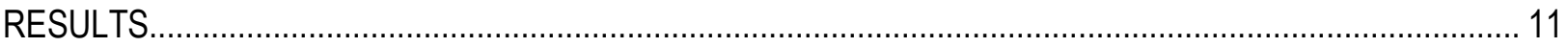

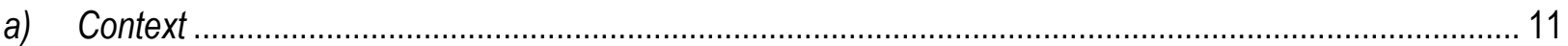

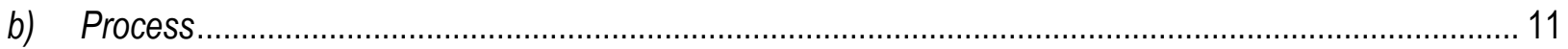

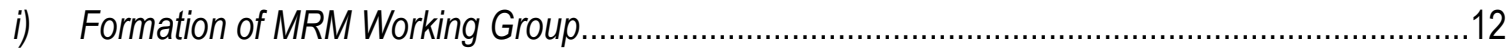

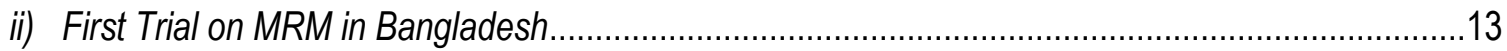

iii) Further Trial on MRM at Public and NGO Health Facilities ..........................................................14

iv) Approval Process for Local Manufacturing of MR Medicines....................................................... 16

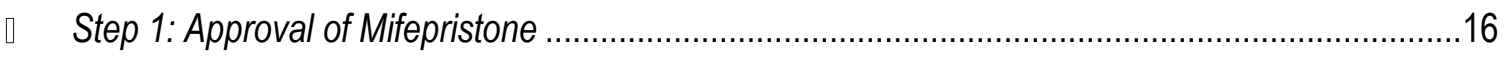

[ Step 2: Approval of Mifepristone-Misoprostol Combination Pack ...................................................17

[ Challenges During Getting Approval for Manufacture, Sell, and Administration of MR Medicines,

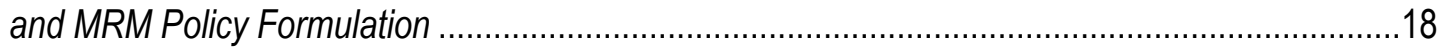

c) Content:

i) Integration of MRM in National MR Program in Bangladesh....................................................... 18

ii) Development of MRM

Guideline. 18

ii) Current Situation of MRM Services in

Bangladesh. .18

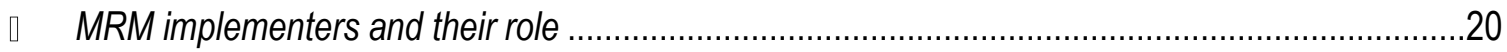

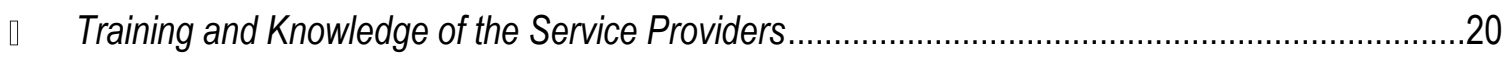

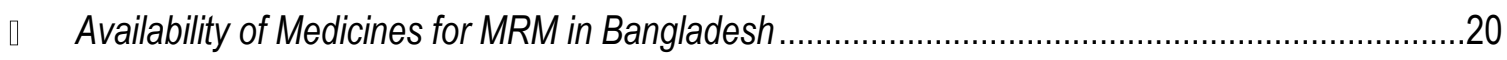

d) Current Implementation Challenges in MRM Service Provision........................................................... 21

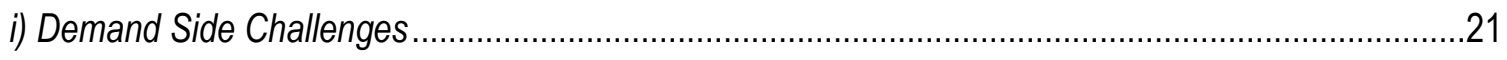

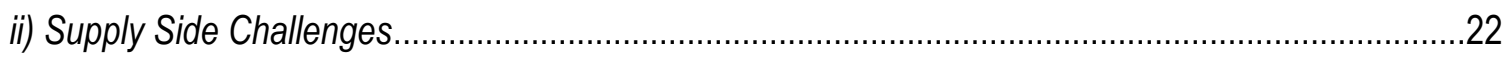

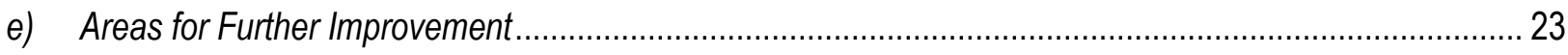

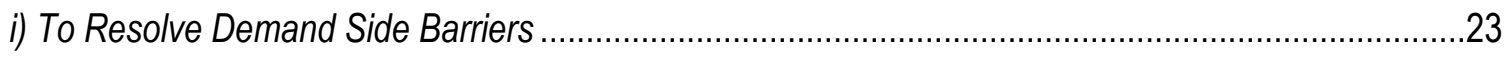


ii) To Resolve Supply Side Barriers. .23

REFERENCES.

25

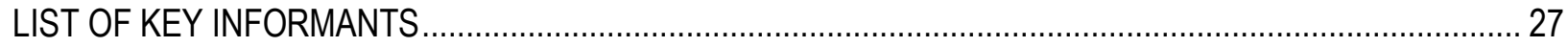

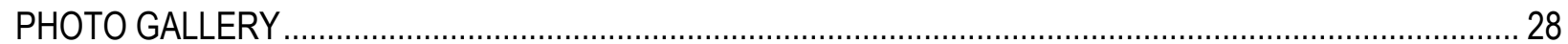




\section{LIST OF FIGURES}

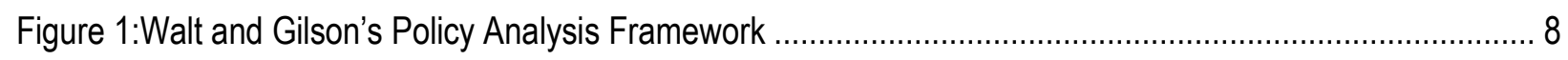

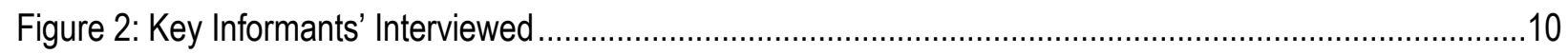

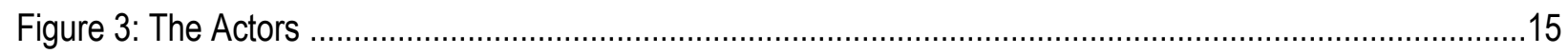

Figure 4: Currently Available MR Medicines (Generic Names) in Local Market................................................24 


\section{ACKNOWLEDGMENTS}

We acknowledge support from the STEP UP (Strengthening Evidence for Programming on Unintended Pregnancy) Research Programme Consortium under which this research protocol was implemented. STEP UP was funded by UKaid from the Department for International Development (DFID), grant number SR1111D-6. icddr,b acknowledges with gratitude the commitment of UKaid to its research efforts.

icddr,b is also grateful to the Governments of Bangladesh, Canada, Sweden and the UK for providing core/unrestricted support. 


\section{LIST OF ABBREVIATIONS}

BAPSA Bangladesh Association for Prevention of Septic Abortion

BDT Bangladeshi taka

BNF British National Formulary

BSMMU Bangabandhu Sheikh Mujib Medical University

BWHC Bangladesh Women's Health Coalition

DCC Drug Control Committee

DD Deputy Director

DDFP Deputy Director of Family Planning

DGDA Directorate General of Drug Administration

DGFP Directorate General of Family Planning

DGHS Directorate General of Health Services

FPAB Family Planning Association of Bangladesh

FWV Family Welfare Visitor

GoB Government of Bangladesh

KII Key Informant interview

LMP Last menstrual period

mcg Microgram

$\mathrm{MCH} \quad$ Maternal and Child Health

MCWC Mother and Child Welfare Centre

MO Medical Officer

MRM MR with Medication

MSB Marie Stopes Bangladesh

MSD Marketing and Sales Department

MVA Manual vacuum aspiration

NGO Non-governmental organizations

NTC National Technical Committee

OGSB Obstetrics and Gynecological Society of Bangladesh

PAC Post-abortion care

PM Program Manager

RHSTEP Reproductive Health Services Training and Education Program

RTI Reproductive tract infection

STI Sexually transmitted infection

TOT Training of the trainers

TSC Technical Sub-Committee 
USFDA United States Food and Drug Administration

WHO World Health Organization 


\section{INTRODUCTION}

Menstrual Regulation (MR), an interim method of establishing non-pregnancy for women who are at risk of becoming pregnant irrespective of whether conception has occurred or not [1], was introduced in Bangladesh in 1970 s as a strategy to reduce maternal morbidity and mortality associated with unsafe abortion [2, 3]. MR is usually conducted without a confirmatory pregnancy test, within 10 weeks of a missed menstrual period by paramedics and within 12 weeks of a missed menstrual period by medical doctors [2, 4]. The services are provided free of cost at primary, secondary and tertiary level public health facilities using manual vacuum aspiration (MVA).

However, women in Bangladesh face a range of barriers when accessing safe MR services that includes: high cost of MR at private hospitals and clinics, untrained private providers, inadequate equipments at some private facilities, and underlying social stigma [5]. Findings show that an estimated $26 \%$ of women seeking MR services each year are turned away by facilities due to various reasons, such as the woman's last menstrual period (LMP) limit exceeding the legal time limit for MR service provision, or provider bias when women have not yet had a child, are considered too young, or do not have their husband's consent [5]. In these circumstances, women are likely to resort to alternative methods of MR.

In light of this, there was a critical need to strengthen the national MR programme with a focus on policy and programmatic aspects to address the issues of inequitable access and to ensure quality of care. Following this, the initiative "Strengthening the National Menstrual Regulation Programme for Reduction of Maternal Mortality and Morbidity in Bangladesh" was launched by World Health Organization (WHO) for the period of December 2007-December 2011, with the financial support from the Netherlands Ministry of Development Cooperation and in partnership with the Government of Bangladesh and MR NGOs [6].

Under this project, a framework for developing the national MR guidelines was jointly drafted by the Directorate General of Family Planning (DGFP), Technical Advisory Committee (TAC) members, and WHO. As an input for the development of the national MR guidelines, WHO shared guidelines developed by them and its partners and those used in other countries in Asia, Europe and Africa with the support from WHO. Finally, in September 2011, the national MR guidelines of Bangladesh were developed in English [6].

Later, following the necessity of developing MR guidelines in Bengali, Marie Stopes Bangladesh in collaboration with the DGFP took the initiative on refining and translating the national MR guidelines into Bengali. Again with the financial support from the Netherlands Ministry of Development Cooperation and in partnership with the Government of Bangladesh, and Marie Stopes Bangladesh, a final draft of the national MR guidelines in Bengali was developed and published in December 2013 [7]. The guidelines were designed to assist programme managers and service providers in better implementing the existing national MR policy. 
The introduction of MR with medication (MRM) was the next step towards promoting women's equitable access to quality MR services in Bangladesh. Until 2012, manual vacuum aspiration (MVA) had been the only option for conducting MR in Bangladesh, yet this method is not suitable or acceptable to all women. In November 2013, based on evidence from a study conducted by icddr,b that indicated that MRM was a safe, acceptable alternative to MVA, the decision was made by the DGFP to introduce the drug combination of mifepristonemisoprostol for MRM into the country's national MR program [8]. This drug combination may be used within/up to 9 weeks of the woman's last menstrual period, is more discreet than MVA, and has fewer side effects [8]. Following this decision, a memo regarding the approval of MRM in Bangladesh was circulated by the DGFP in February 2015. The memo designated the 9 week timeframe permitted for MRM use, and that it may be administered by service providers who have receive proper training on MRM [4]. Shortly before approval of the introduction of MRM into the national MR program, the DGDA had approved local manufacturing of the combination pack of mifepristone and misoprostol for MR, enabling a local supply of the drug.

As of April 2017, the DGFP has completed a portion of the service providers' training on MRM. To conduct this training activity, DGFP included two participants from each of the 96 Maternal and Child Welfare Centres (MCWC) of Bangladesh. Therefore, a total of 192 Medical Officers, including Medical Officer (Clinic) \& Medical Officer (MCH-FP), and Family Welfare Visitors (FWVs) from 71 MCWCs have already received the training. Another 309 service providers from all primary, secondary, and tertiary level health facilities of Barisal division have also been trained by the government. In addition, staffs from all UH\&FWCs from five districts of Khulna and Barisal divisions have been trained [9]. The DGFP is currently in the process of developing procurement agreements for the mifepristone-misoprostol combination pack in order to introduce MRM universally at public health facilities through Marie Stopes, Bangladesh and Population Council, Bangladesh with funding support from the Embassy of the Kingdom of the Netherlands (EKN) [9]. A number of local pharmaceutical companies currently manufacture the mifepristone-misoprostol combination while a few manufacture mifepristone alone.

Despite the significant progress that the government of Bangladesh has made towards introducing MRM into the national health program, there has been no systematic documentation on the introduction of MRM in Bangladesh, and on the approval process of local manufacturing of the mifepristone-misoprostol combination for MR. This research study was an initiative to document the entire process of introducing MRM in the country through a stakeholder analysis. In addition to the process documentation, a situation analysis and mystery client visit were conducted as part of this project to generate evidence on how approval of MRM has influenced the availability and provision of MR services through private pharmacies and medicine sellers in Bangladesh. 
Figure 1: Walt and Gilson's Policy Analysis Framework

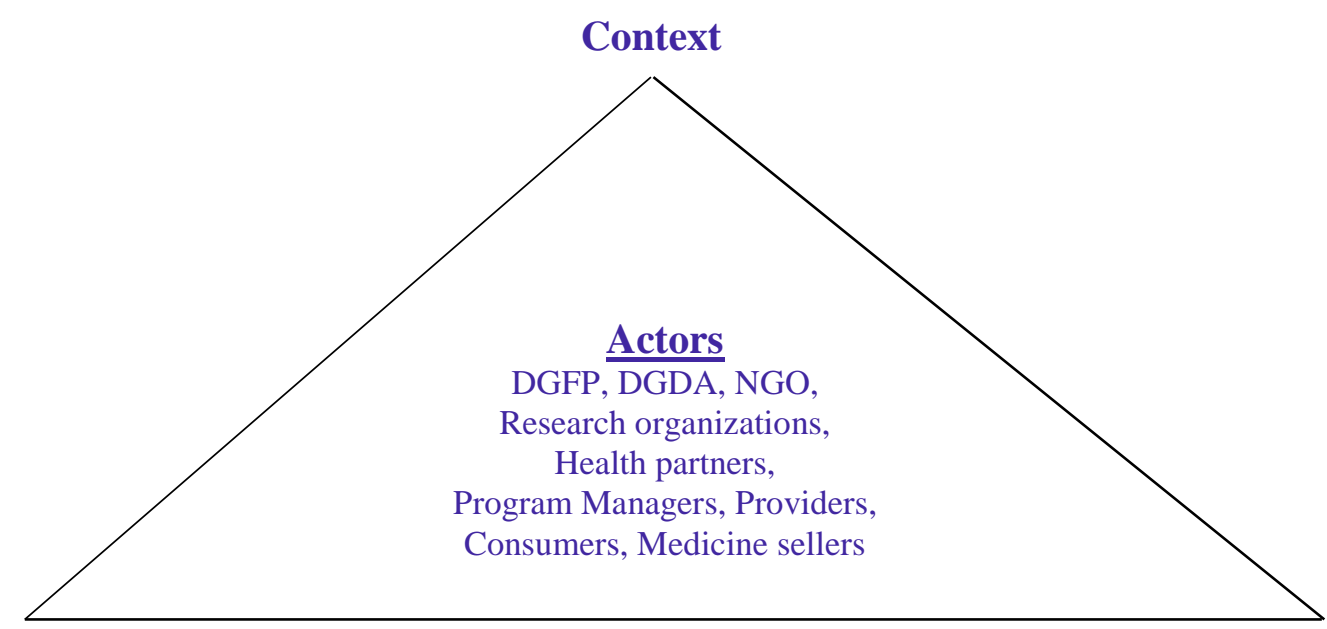

\section{Content}

Process

In this report, only the findings from the stakeholder analysis will be presented. The report is written following the policy analysis framework by Walt and Gilson, and has been categorized in four different parts: a) Context, b) Process, c) Content, and d) Actors. 


\section{METHODS}

\section{Study Design:}

The stakeholder analysis was conducted using a qualitative study approach. Semi-structured questionnaires were used to conduct interviews with the key stakeholders. Information was collected to explore the roles of different actors, the decision making process, and the contextual factors that led to the introduction and approval of MRM in Bangladesh.

\section{Data Collection:}

Two different data collection procedures were used:

- Key Informant Interviews (KIIs) were conducted with representatives from different government institutions, private organizations, non-government organizations, health development partners and technical assistance agencies. The key informant interviews were conducted from 18 April to 31 May, 2015.

- A round table discussion was held with the similar key informants on 30 November, 2015 to discuss some of the issues and gaps identified during key informant interviews.

\section{Categories of Key Informants:}

- Policymakers from government and non-governmental organizations (NGOs) who were involved in the decision making of MRM introduction in the country and in its approval process.

- Implementers from government, and NGOs who were involved in implementing MRM services in the country.

- Pharmaceutical companies who were manufacturing the mifepristone-misoprostol combination pack locally.

- Medicine sellers who were involved in the promotion and sale of mifepristone-misoprostol combination for menstrual regulation.

- A random selection of mystery clients who participated in the situation analysis part of the study.

\section{Selection Process of Study Participants:}

- Review of existing literatures and listing of members of the MRM working group in Bangladesh.

- Brainstorming with the MRM working group members to identify more participants from various networks who participated in or supported the introduction, approval and implementation of MRM introduction in Bangladesh. 
Figure 2: Key Informants Interviewed
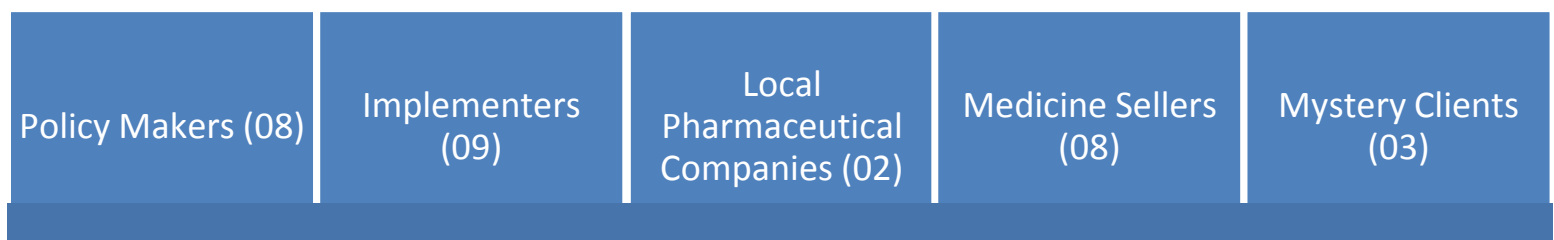

\section{Data Analysis:}

Data analysis of the study was performed thematically. A transcript of each tape-recorded interview was prepared and then reviewed by a qualitative researcher to gain familiarity with the data and to highlight key issues, common ideas, and recurring concepts. The data was then systematically coded, indexed, and synthesized to enable interpretation of the findings. This entire work was done by a number of researchers to assess reliability of the data. Following this, key themes and sub-themes were identified by drawing attention to priority issues based on the aims of the study. Findings on the same issues discussed by various participants were compared to strengthen their validity and to assess their similarities and differences. Emerging themes and sub-themes were then analyzed to understand the potential roles of key stakeholders in the introduction, approval and implementation of MRM in Bangladesh. No specific qualitative data analysis software was used for the data analysis. 


\section{RESULTS}

Findings from the key informant interviews indicated some key factors that brought about the introduction of menstrual regulation with medication in Bangladesh, and are presented here following the four parts of Walt and Gilson's policy analysis framework: a) Context; b) Content; c) Process; and d) Actors.

\section{a) Context:}

Findings from the interviews with key stakeholders showed that introduction of MRM in Bangladesh were influenced by the following contextual issues:

- Some medicines, especially Gynaecosid (used to treat secondary amenorrhea) was easily available in local market that the women were using for regularize menstruation, if it was missed. This medicine was often imported from the neighboring countries that had unregulated sale in the local market by the medicine sellers. As a result, indiscriminative use of this medicine by the clients was increased.

- An increased incidence of complications due to usage of inappropriate medicines was revealed. According to a study conducted in 2014, an estimated 257,000 women were treated for complications of induced abortions [10] which were found 231,400 in 2010 [5].

- Performance of MVA by untrained providers and traditional healers in unhygienic environments caused high morbidity among many women. Many of these MVA procedures were incomplete and unsuccessful. Evidence showed that, roughly 120 out of every 1,000 MR procedures results in complications that are treated in health facilities in 2010 [5].

- Complications from MVA likely result from improper use of MVA equipment, use of unsterile equipment, other unhygienic practices, and use of a MVA syringe more than the recommended 50 times [11].

- The cost for MR procedures using MVA was relatively high. Safe and effective conduction of surgical MR using MVA required substantial investments in adequately trained and skilled personnel, wellequipped and private MR procedure rooms, clean and sterile instruments, logistics, and medications in proper dosage.

- Economic, cultural and social barriers limited women's access to safe MR services using MVA. Women's fear of undergoing a surgical procedure and privacy concerns related to the social stigma of MVA often discouraged them to seek the service within the legal time limit, which in turn caused a higher number of rejections. Evidence also showed that women identified social stigma and fear of the procedure as the main obstacles to seeking safe MVA services [12].

- Many women were unaware about the information regarding safe surgical MR provision by MVA, such as from where to seek these services, and about the legal time limit of MR service provision by MVA. 
- Due to lack of awareness of the magnitude of risks related to unsafe MVA, women often sought services from untrained providers and consequently suffered from complications which sometimes lead to death.

- Although MVA is safe procedure, it is invasive and carries risk of complications; a non-invasive, more suitable, technologically simple, and easy-to-use alternative method of MR was desired by both women and providers.

b) Process:

Since 1980's, Gynaecosid as well as other medicines were being used for regulation of menstruation in Bangladesh. These medicines were available in local pharmacies and were easily accessible to the community. Yet due to lack of awareness about safe MR service provision, unregulated sale, and indiscriminative use of these medicines, high rates of maternal morbidity and post-MR complications were happening widely. Stakeholders from different NGOs, programme implementers, as well as professional bodies saw the acute need for a solution to this situation. They planned to develop a policy guideline to control the unregulated sale and rampant misuse of these medicines.

In 2002, mifepristone - a medicine that brings on a period - received approval in India for the purpose of using for menstrual regulation. Following that, there was a growing interest among Bangladeshi stakeholders to introduce mifepristone for MR in Bangladesh. In 2004, the WHO launched safe abortion guidelines through a workshop held in Bangkok, where two representatives from Bangladesh were present. Soon after their return, these representatives submitted a proposal to the National Technical Committee (NTC) of the Directorate General of Family Planning (DGFP) to introduce menstrual regulation with medication (MRM) in Bangladesh [13]. However, the committee expressed their concerns about the possible side effects of MR medicines, and suggested to think strategically before submitting any further proposal on MRM.

\section{i) Formation of MRM Working Group:}

Advocacy for MRM was initiated by Marie Stopes Bangladesh along with other NGOs who were already involved in providing MR services at the community level. As part of this initiative, in 2007, health professionals and researchers were encouraged to develop an MRM Working Group, a network of professional bodies who were keen to introduce MRM in Bangladesh. The ultimate objective of the MRM working group was to act as an advocate for approval of MRM in the country. They worked as a pressure group in order to establish and increase the access of MRM as an easy, safe, and affordable alternative to surgical MR (MVA).

The MRM working group played a vital role for advocating the approval of MRM in Bangladesh. As part of their initiatives, in December 2007, they organized a seminar and roundtable on "MR with Medication: Relevance, Issues, and Opportunities" with technical assistance from Ipas and Gynuity [14]. Leaderships from the DGFP, 
DGHS, the obstetrician/gynecology community, research organizations, MR service providers, reproductive health NGOs and development partners were present and actively participated in the roundtable discussion [14]. In the roundtable, representatives from the Family Planning Association of Bangladesh (FPAB); Bixby School of Public Health, University of California, Berkeley, USA; Gynuity Health Projects, USA; and Concept Foundation, discussed the relevance of MRM and introduction of the combination of mifepristone-misoprostol for MR services in Bangladesh [14].

During the seminar and roundtable, one of the leading personnel from Obstetrics and Gynecological Society of Bangladesh (OGSB) did informing about the approval of MR medicines in some of the developed countries like USA and Europe, and also about the ongoing trials on MRM in Nepal. The discussion yielded an overall consensus that MRM can be introduced in Bangladesh as an alternative to MVA [14]. Yet some key stakeholders expressed their concern that introduction of MRM would raise debate around MR services in the country -- most importantly, the sensitivity of MR issue in Bangladeshi society and possible negative public reactions toward MRM introduction. They also underscored the need for organized and careful steps to introduction. Based on the discussions, comments, and suggestions, and to implement the consensus of the roundtable participants to explore the use of MRM in Bangladesh through research, three initial steps were recommended:

Step 1: Review international experiences with MRM.

Step 2: Prepare for research on mifepristone and misoprostol in Bangladesh; and

Step 3: Conduct clinic-based research.

\section{ii) First Trial on MRM in Bangladesh:}

In 2008, the combined regimen of mifepristone and misoprostol, Medabon ${ }^{\circledR}$, were nationally approved and registered for medical abortion and use in public health facilities in Nepal [15]. Simultaneously, mifepristonemisoprostol combination pack was made available in the South Asian region. These initiatives and momentum in the neighboring countries subsequently facilitated positive attitudes within the Directorate General of Drug Administration (DGDA) of Bangladesh to introduce and manufacture MR medicines in the country.

Meanwhile, icddr,b led a trial with Gynuity health projects titled 'Acceptability and Feasibility of Mifepristone and Misoprostol for Menstrual Regulation in Bangladesh' from July 2009 to April 2010 on menstrual regulation with mifepristone and misoprostol combination [16]. Several MR service-providing NGOs including BAPSA (Bangladesh Association for Prevention of Septic Abortion); BWHC (Bangladesh Women's Health Coalition); FPAB (Family Planning Association of Bangladesh); MSB (Marie Stopes Bangladesh); and RHSTEP (Reproductive Health Services Training and Education Program), participated in the trial. 
The objective of conducting the trial was to assess women's and providers' acceptability and feasibility of simplified mifepristone-misoprostol combination regimen for menstrual regulation [16]. Findings from the study showed that the combination drug for MR was highly acceptable to women; the majority of the participating women (93 percent) chose to obtain MR through MRM and most of them (92 percent) were satisfied with this procedure. Providers faced initial challenges and concerns, particularly about additional counseling requirements and lack of control over the final outcome, but became more confident after successful use of the proper regimen of the combined medicines [16]. The study recommended that mifepristone-misoprostol combination can safely be offered within the existing menstrual regulation services system in urban and periurban areas in Bangladesh. The trial also acted as a platform to increase providers' knowledge and interest in this approach and in creating a group of "Local Experts"[10].

In November 2010, a dissemination meeting on the above study findings was held in Dhaka, where the stakeholders expressed their satisfaction related to MRM [17]. Simultaneously, some of them also raised concerns regarding indiscriminative use of MR medicines due to unregulated management of the drug sellers, easy accessibility of MR medicines to the clients, and the capacity of government service providers to provide MRM services. Apart from these concerns, the stakeholders agreed to move forward for MRM approval in Bangladesh [17].

\section{iii) Further Trial on MRM at Public and NGO Health Facilities:}

With time, the MRM working group increased in size. As part of their regular activities, they continued working with different key stakeholders in the relevant area, such as the Directorate General of Family Planning (DGFP) and Directorate General of Drug Administration (DGDA), and initiated several meetings. Key actors from the MRM working group conducted series of discussions with prominent obstetricians \& gynecologists, government officials, and representatives from different NGOs involved in MR service provision. The Obstetrical and Gynecological Society of Bangladesh (OGSB) strongly advocated for MRM. This resulted in increase support for introducing MRM in public sector facilities in Bangladesh. Hence, the DGFP was interested to see more research on MRM conducted in public sector health facilities.

In January 2011, in its $57^{\text {th }}$ meeting, the National Technical Committee (NTC) at the DGFP asked the relevant stake holders to conduct pilot studies on 'MRM in public sector health facilities' [18]. In response to this proposal, icddr,b, Marie Stopes Bangladesh, and Population Council submitted two separate concept notes to the Bangladesh Medical and Research Council (BMRC). Gynuity Health Projects and WHO agreed to fund the two pilot studies. 


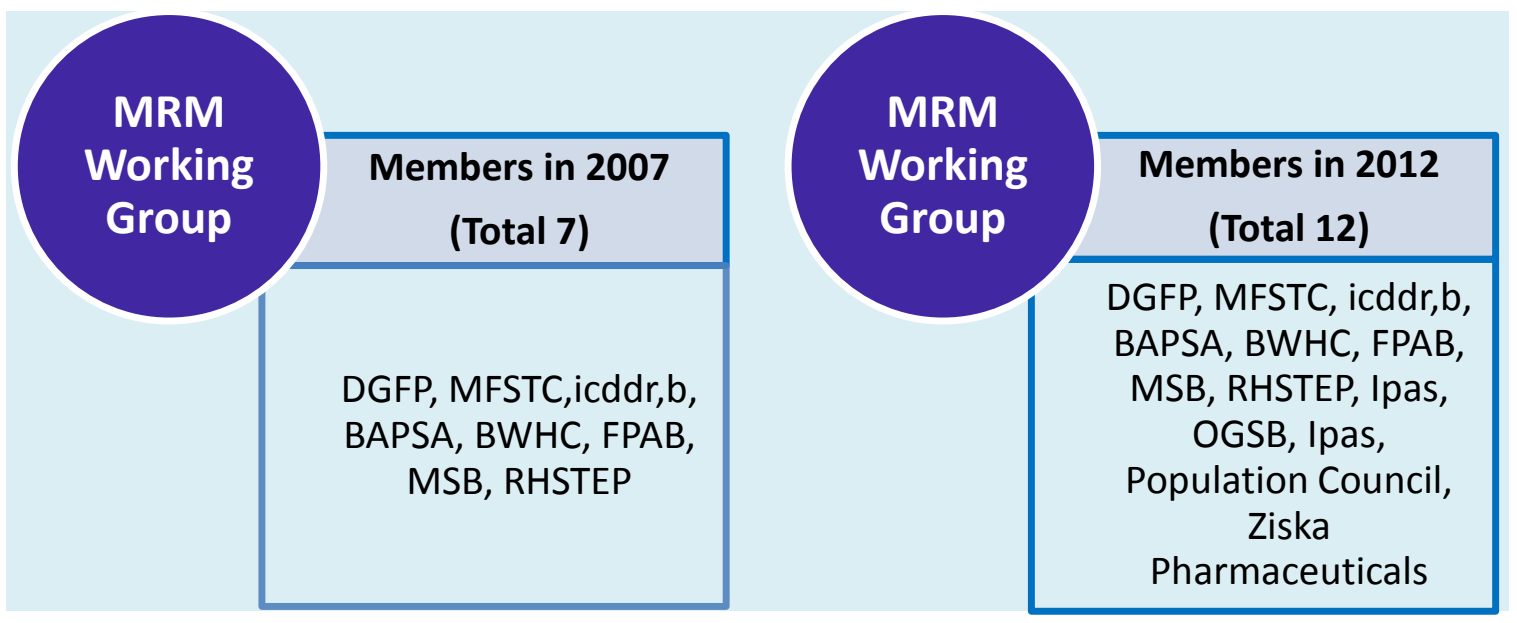

Between January 2012 and June 2013, Population Council and Marie Stopes, Bangladesh conducted an operations research study to test the feasibility and accessibility of introducing menstrual regulation with medication in Bangladesh as well as women's satisfaction and overall quality of care. The study was conducted at eleven public health facilities (three MCWCs and eight FWCs) and two Marie Stopes clinics in eight districts of Dhaka Division [18]. Findings from the study showed that, given the option between MRM and MVA, the majority of the women selected MRM for reasons of greater safety and confidentiality. Investigators of the study recommended that MRM be incorporated into the national family planning program of Bangladesh for the safety, good health, and well being of women [19].

Between November 2012 and June 2015, Gynuity Health Project and icddr,b initiated another study on MRM in 24 public health facilities (one specialty hospital, 10 secondary and 13 primary level facilities) of six divisions in Bangladesh. This study offered mifepristone and misoprostol combination for MR to the clients and finally was able to enroll 1,744 women who received the combined medicines for MR services from the selected facilities [20]. Findings from the study showed that most women (96.3\%) had a successful uterine evacuation without the need for a surgical intervention. [20].

Another study was conducted between April and October 2013 by the OGSB in collaboration with the DGFP with support from World Health Organization [21]. The study was implemented in five purposively selected health facilities in Dhaka city. Women who came for MR were given the opportunity to choose either MVA or MRM with mifepristone-misoprostol combination. In that study, 500 women received the combined regimen of mifepristone and misoprostol to establish their menstruation. Among them $69.11 \%$ returned for follow up visit and checkup. Findings from the study showed that, $7.74 \%$ of the women with mifepristone and misoprostol combined regimen did not get the expected result of the medicines and they had to go further for MVA or to be referred for dilatation and curettage (D\&C/MVA) services to establish their normal menstruation [21]. 


\section{iv) Approval Process for Local Manufacturing of MR Medicines:}

In 2008, misoprostol was approved in Bangladesh for the treatment of postpartum hemorrhage (PPH). Evidence from other countries had also shown that misoprostol could be used for early termination of pregnancy [22]. Simultaneously, a combination of misoprostol and mifepristone had been shown to work even more effectively, and was found to be acceptable and feasible for conducting MRM in Bangladesh [16]. However, mifepristone was not an approved and registered medicine by the Directorate of Drug Administration (DGDA), Bangladesh; therefore, separate approval was needed for mifepristone and the combination of mifepristone-misoprostol to introduce these combination medicines for use in MR in the country.

\section{- Step 1: Approval of Mifepristone}

The MRM working group played a vital role in the process of approval of local manufacturing of mifepristone. On behalf of the MRM working group, the president of Obstetrical and Gynecological Society of Bangladesh (OGSB), initiated the process of registering mifepristone and requested several pharmaceutical companies to manufacture it locally. As a result, one of the pharmaceutical companies took the initiative to manufacture and register mifepristone.

The MRM working group co-opted the pharmaceutical company as working group member. However, approval from the DGDA was needed prior to manufacturing and marketing this new medicine in the country. As a primary step to this, and to facilitate the process, a written proposal was submitted to the Technical SubCommittee (TSC) of the DGDA, which gives approval of any new medicines to be manufactured in the country.

A formulation of the medicine (including international references), and findings from the completed research studies on trial of the medicine were also needed to submit with the proposal. International references were taken from United States Food and Drug Administration (USFDA), and British National Formulary (BNF). Trial findings were collected from the research study titled "Acceptability and Feasibility of mifepristone-misoprostol for Menstrual Regulation in Bangladesh", conducted by icddr,b and was a joint collaboration between icddr,b and Gynuity Health projects [16].

The pharmaceutical company submitted the formulation of the medicine along with all necessary documents and evidence to the TSC if the DGDA to receive approval from the Drug Control Committee (DCC). Finally, on 13 September, 2012, mifepristone was approved by the Drug Control Committee (DCC) to be manufactured, sold, and administered locally [23]. The entire process took approximately a year from the date of submission of the documents by the pharmaceutical company to the TSC until its final approval. 


\section{- Step 2: Approval of Mifepristone-Misoprostol Combination Pack}

After receiving approval of mifepristone only, the MRM working group initiated the process of approval of local manufacturing of mifepristone-misoprostol combination pack for MR. A combination pack was a specific focus of the approval as it was identified as a way to prevent indiscriminate or incorrect use of the medicines when those were used separately. The apprehension was that, if mifepristone and misoprostol were dispensed in separate packets, users may use only one of them which would decrease the effectiveness and eventually lead to increased incomplete MR, which is a health risk for women. This concern was already aggravated by existing over the counter sale of MR medicines by medicine sellers. It was not an easy task for the relevant stakeholders to get approval of the mifepristone-misoprostol combination pack from the Technical subcommittee (TSC) of the Directorate General of Drug Administration (DGDA). The TSC retained several concerns:

- $M R$ is a socially sensitive issue in Bangladesh.

- MR related complications may increase due to incomplete MR or method failure resulting from irrational or improper use of the drugs.

Members of the MRM working group, especially the obstetricians and gynecologists, exerted much effort in advocating for the combination pack of mifepristone and misoprostol and in convincing the DGDA to approve this. They emphasized that though sensitive, but MR has been an approved service in Bangladesh since 1979, was introduced as a backup for ineffective use of contraceptives, and that MRM is in fact a safer and effective alternative method to MVA for conducting MR.

To encourage the TSC to recognize these facts and approve MRM, one of the pharmaceutical companies presented them with evidence from the pilot study on MRM at NGO sector health facilities conducted by icddr,b, which was the only completed study at that time that revealed the findings on the feasibility and acceptability of MRM in Bangladesh [16].

The TSC of the DGDA then asked for two recommendation letters from the Head of the Department of Obstetrics and Gynecology, Dhaka Medical College \& Hospital and from the Chairman of Obstetrics and Gynecology, Bangabandhu Sheikh Mujib Medical University in Dhaka in favor of approving the mifepristonemisoprostol combination pack for MR in Bangladesh.

It was unusual for the DGDA to request recommendation letters in favor of a particular medicine from any authority as a precursor to approval. However, because the mifepristone-misoprostol combination does include abortifaecient medicines, and since abortion is a legally restrictive and sensitive issue in Bangladesh, the DGDA requested the letters prior to approving the drug as an additional layer of scrutiny. 
In February 2013, the culmination these efforts finally brought success and the pharmaceutical company received approval of the mifepristone-misoprostol combination for MR to manufacture, sell, and administer it locally [24].

- Challenges during getting approval for manufacture, sell, and administration of MR medicines, and MRM policy formulation

During getting approval for manufacture, sell, and administration of MR medicines, and MRM policy formulation, following issues and concerns raised among relevant key stakeholders:

- Inappropriate or improper use of MR medicines by clients;

- Indiscriminate or random use/sale of MR medicines by medicine sellers, and local service providers;

- Whether there would be a delay in receiving approval of the MR medicines from the DGDA and other drug regulatory and approval authorities considering the restrictive law and social barriers to abortion in the country.

c) Content:

i) Integration of MRM in National MR Program in Bangladesh

The National Technical Committee (NTC) of Directorate General of Family Planning (DGFP) approved MR with mifepristone-misoprostol combination at its $61^{\text {st }}$ meeting held on 26 November, 2013 [25]. The next priority task was to formally integrate MR with mifepristone-misoprostol combination into the National MR program.

During that time (from January 2012 to June 2013), an operations research study "Introducing Medical Menstrual Regulation in Bangladesh" was conducted by the Population Council in collaboration with Marie Stopes Bangladesh and the DGFP in public facilities and NGO facilities providing MR services [19]. The aim of the study was to test the feasibility of introducing MRM in Bangladesh as well as to assess the accessibility of mifepristone and misoprostol combination in health facilities of Bangladesh [19]. Findings of the study revealed that of the 2,976 women who sought MR services in health facilities, $63 \%$ of them selected MRM when offered a choice between MRM and MVA [18]. Women who choose MRM over MVA indicated following reasons for choosing this option:

- Less invasive (54\%),

- Less expensive (52\%),

- Did not require any surgical intervention (34\%), and

- Perceived it as less risky (29\%) [19]

The study also included observations of MR service providers were in order to assess the quality of their service delivery. Findings showed that the overall quality of services for MRM was high; two-thirds of the women who received MRM services from the health facilities were satisfied with the process of MRM and 
quality of care provided by the service providers [19]. The evidence from this study indicated that introducing MRM services in Bangladesh was acceptable and feasible, particular focus on the high level of satisfaction among MRM users. Study findings were shared during a dissemination meeting with key stakeholders from Directorate General of Family Planning (DGFP), Directorate General of Health Services (DGHS), Obstetrical and Gynecological Society of Bangladesh (OGSB), and different NGOs that provide MR services. Findings from the study helped relevant actors to take the initiative on integrating MRM into the national MR program [19].

In February 2015, DGFP circulated a memo regarding the approval of MRM in Bangladesh. This circular stated that within 6-9 weeks of women's last menstrual period, 200 milligrams of mifepristone and 800 micrograms (4 tablets of $200 \mathrm{mcg}$ ) of misoprostol may be used for MR [4]. For the most effective result, at first, $200 \mathrm{mg}$ tablet of mifepristone should be taken orally followed by of the 800 micrograms of misoprostol in 24 hours, either buccally, sublingually, or vaginally [4]. In addition, the memo also indicated that MR service providers should receive proper training on MRM service delivery prior to providing this service to their clients [4].

\section{ii) Development of MRM Guidelines}

Findings from this stakeholder analysis revealed that in order to train and educate service providers and to provide consistent information among different cadres of service providers, development of a precise service delivery guideline for administering MRM was essential. It was understood by the government and the stakeholders who were already involved in MR service provision.

After a series of meetings, the officials of the MCH-Services Unit of the DGFP took the lead in the development process of the MRM guidelines. Members from the OGSB actively participated and provided valuable suggestions and guidance in developing the guideline. Population Council and Marie Stopes Bangladesh provided technical support and commitment to MRM program that helped in advancing its development. A Project Advisory Committee was developed and members of the committee provided continuous input during its development phase and ultimately gave approval for the guidelines.

The guideline was mainly adapted from the WHO "Clinical practice handbook for Safe abortion". Additionally, program implementation strategies of different countries and experiences from organizations providing MR services in Bangladesh were also considered during development of the guidelines. The final version of the service delivery guidelines was published in September of 2015 and entitled, "Bangladesh National Service Delivery Guideline on Menstrual Regulation with Medication (MRM)" [26]. 


\section{iii) Current Situation of MRM Services in Bangladesh}

\section{- MRM implementers and their role}

To conduct this stakeholder analysis, nine implementers were interviewed and out of them, six were directly involved in MRM service provision. Findings indicated that, with permission from Directorate General of Family Planning, service providers from NGO health facilities were involved in the initial trial of MRM service provision since its introduction in the country. Service providers from public health facilities initiated MRM service provision only after receiving the formal approval from the government of Bangladesh. Among the NGOs, the Bangladesh Association for Prevention of Septic Abortion (BAPSA), Reproductive Health Services Training and Education Program (RHSTEP), Obstetrical and Gynecological Society of Bangladesh (OGSB), and Marie Stopes Bangladesh (MSB) were the pioneer organizations to roll out of the new MRM program in Bangladesh. The service providers offered various MRM services to the women, such as counseling, prescribing medicine, complication management, post-abortion care (PAC), monitoring and supervision, advocacy, and training services related to MRM.

\section{- Training and knowledge of the service providers}

Six (three from NGOs and three from public health facilities) out of nine of the service providers who were directly involved in MRM service provision, and were interviewed for this stakeholder analysis, had received formal orientation and training on MRM before providing client services. Among them only one service provider received formal training from abroad. Three participants from public health facilities received training as part of the icddr,b research project. Before conducting the research, icddr,b arranged one and half day clinical trainings on MRM for the service providers of the public health facilities. All of the NGO providers $(n=03)$ received necessary training as part of initiation of MRM in the country. These three NGOs were OGSB, Marie Stopes and BAPSA, who were the key members of the MRM working group and took active part in the process of MRM introduction and policy approval in Bangladesh.

\section{- Availability of Medicines for MRM in Bangladesh}

To document the availability of MRM medicines in Bangladesh, key informant interviews were conducted with two different groups of respondents including medicine sellers and mystery clients. Since survey responses do not always reflect real-life practices, mystery client encounters were utilized in the 'Situation Analysis' part of this study to assess the actual provision of mifepristone-misoprostol combination regimen by the medicine sellers. The mystery clients were field research team members who were specially trained to give standardized responses during their interaction with the medicine sellers. The purpose of conducting interviews with medicine sellers and mystery clients was to collect information on availability, cost, and supply chain mechanism of mifepristone-misoprostol combination regimen in local pharmacies. 
Information provided by medicine sellers and mystery clients revealed that cost of available medicines for MR in the market ranges from 15 taka to 300 taka (BDT) (equivalent to $\$ 0.20$ to $\$ 3.80$ USD). Findings from mystery client interviews indicated that cost of medicines usually does not discourage the women from purchasing them because of their prevailing desire to restore their normal menstrual cycle and overcome a crisis situation.

The medicine sellers often capitalize on this emergency situation of the clients by asking for a higher price than is appropriate. Two main reasons that motivate women to purchase particular MR medicines were the effectiveness of the particular medicine and women's ability to afford the drug. Mystery client interviews also revealed that not only did the price vary from seller to seller, but so too did the medicine sellers' approach toward the clients vary with different contexts. Seller attitudes varied on topics such as duration of pregnancy and marital status of the clients.

Among all available MRM medicines, MMKit and MTP Kit (mifepristone-misoprostol combination regimen); cytomis and isovant (misoprostol only); and MIF (mifepristone only) were identified by the medicine sellers as the most popular and commonly used medicines. However, emergency contraceptive pills were erroneously identified as MR medicines by some of the medicine sellers.

Figure 4: Currently Available MR Medicines (Generic Names) In Local Market

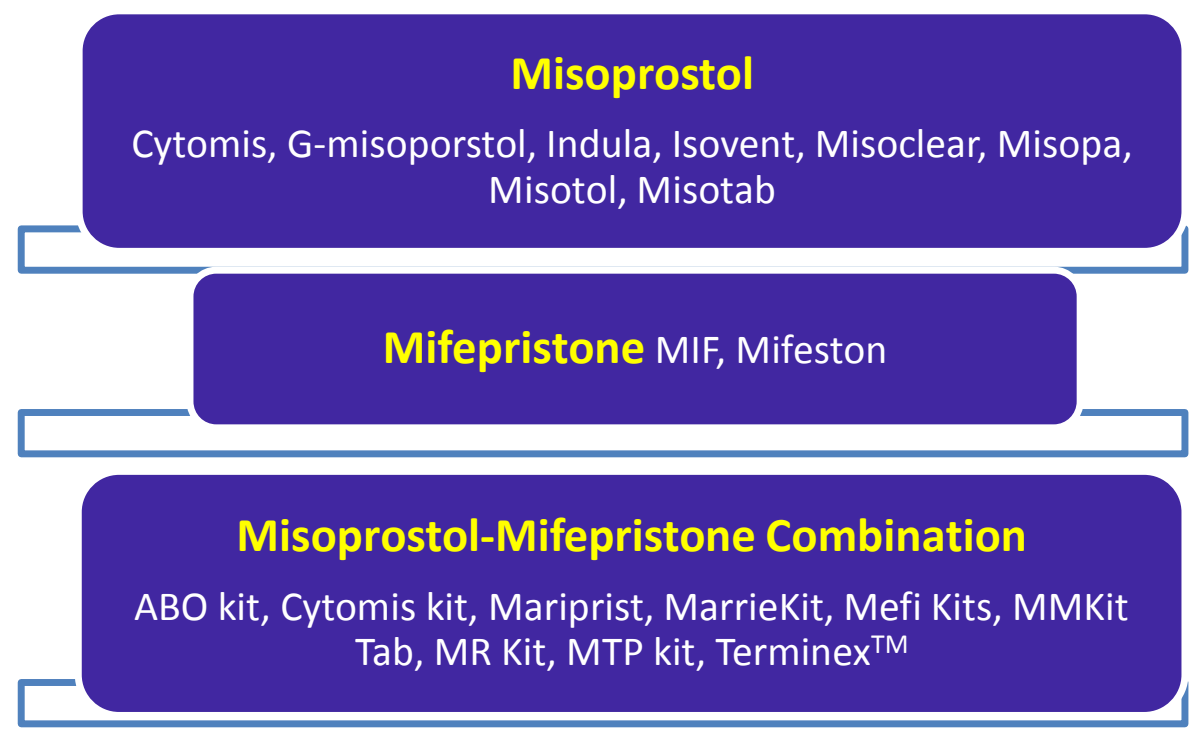

d) Current Implementation Challenges in MRM Service Provision

i) Demand Side Challenges

- Lack of knowledge and awareness of women: Most of the women are unaware about their correct gestational age, proper dose of MR medicines, proper timing of taking the dose, 
appropriate follow-up visits after taking medicines, and post-MR contraceptive methods. All these factors usually lead to repeated unwanted pregnancies.

- Complications of using MR medicines: Women usually have some complications by using MRM including heavy bleeding, high fever, severe abdominal pain etc. Aversion to these complications can discourage women from seeking MRM services who may otherwise need it.

- Motivation of women for MRM: Medicines for MR work comparatively slower than manual vacuum aspiration, and usually takes from 24 hours to three days to work. This sometimes discourages women to seek MRM services, especially those who are from lower socio-economic conditions and live on daily wages, as they don't want to lose their wages for a longer period than necessary. The slow process of performing MR with medicines is a barrier to women's motivation to seek MRM services.

\section{ii) Supply Side Challenges}

- Inadequate knowledge and practice of the informal providers (including medicine sellers, village doctors, homeopaths, and Kobirajs) regarding MRM: Due to informal providers' having improper knowledge of appropriate MRM counseling and complication management, many women suffer from incorrect use of medicines for MR and related complications.

- Indiscriminate and unregulated sale of MR medicines by medicine sellers: Informal providers do not properly screen clients prior to providing MR medicines to them. Moreover, they sell MR medicines without any prescription and without providing women with any counseling. Findings showed that medicine sellers provide MR medicines to the clients beyond the legal time limitation of MRM (up to 9 weeks of gestational age). They were seen to provide medicines for MR even if the women had reached 13 weeks of pregnancy.

- Limited campaigning and field promotion activities on MRM: The Government of Bangladesh has lead limited advocacy efforts to promote MRM, especially in remote and rural areas. This may contribute to low MRM use among women.

- Improper documentation or record-keeping of MRM service provision: A significant number of women are using MRM services, but are not reported due to un-prescribed and unregulated sale of MR medicines at pharmacies by medicine sellers.

- Service providers' reluctance about MRM: Service providers often displayed a reluctance to provide MRM services because they receive no remuneration for providing the service. However, by performing MVA they do receive remuneration. Arranging for providers to receive comparable remuneration for MRM service may motivate them to offer the service with the same emphasis as MVA. 


\section{e) Areas for Further Improvement}

The participants who took part in this stakeholders' analysis suggested some areas of further improvement for sustainability of the MRM program in Bangladesh. These suggestions were provided from two different perspectives:

- to meet demand-side (client-side) barriers

- to meet supply-side (provider-side) barriers

i) To Resolve Demand Side Barriers

- Provide correct and appropriate information about MRM to the clients: Due to inadequate knowledge, improper use of MR medicines by women was widely observed. However, misuse of MRM often occurs because of easy availability and accessibility of medicines at pharmacies where women can be inappropriately offered MR medicines and inadequately counseled on their use. It was suggested that advocating for MRM among the service recipients may be an effective way of raising awareness and knowledge among clients. The study participants proposed a variety of ways of advocating for MRM among the clients:

- Involve government field staff or frontline health workers for field promotion of MRM because of their easy accessibility to women and acceptance among women in the community.

- Arrangement of group meetings with local elites and local government authorities for awareness development about MRM.

- Media campaigning in both print and electronic media, offering information on MRM using easily understandable language (especially for people living in remote, rural, and hard to reach areas.)

- Inclusion of a book chapter on MRM in medical textbooks.

○ Using audio-visual materials for field campaigning.

- Involvement of NGOs and other voluntary organizations in an MRM campaign to raise awareness among women in their networks.

○ Supply of MRM medicines at public health facilities to make them available to women who do seek services.

ii) To Resolve Supply Side Barriers

- Build awareness among frontline health workers or service providers about MRM: informal service providers such as medicine sellers, village doctors, homeopaths, and kobirajs need orientation and training on MRM (especially on counseling, proper use of MR medicines, side effects of MRM and complication management.) These frontline service providers are most often the primary contact person for women when seeking health care services for culturally or socially 
stigmatized health issues including MRM. Due to inadequate knowledge on MRM and its related issues, informal providers (especially medicine sellers) often provide these medicines without adhering to any regulation which ultimately can cause health complications for women.

- Stop providing separate packets of mifepristone and misoprostol for MR: pharmaceutical companies should stop providing mifepristone and misoprostol for MRM separately to the medicine sellers and should promote the combination regimen packs. This is because offering the medicine in separate single packs increases the likelihood that clients will purchase and use a single MR medicine (i.e. either misoprostol or mifepristone alone for MR) which decreases efficacy and increases the risk of incomplete MR.

- Allocate incentives for the trained providers who are authorized to provide MRM services: According to some participants interviewed, often providers are reluctant to provide MRM services because they do not earn any remuneration by providing this service. Meanwhile, they do get remuneration for performing manual vacuum aspiration (MVA). Arranging remuneration for the trained MRM service providers may motivate them to offer both services with equal emphasis.

- Develop strong monitoring and supportive supervision system: Develop a strong monitoring and supportive supervision system to oversee service providers' practices in accordance with the national MRM guideline [26] and to control the unregulated sale of MR medicines by the medicine sellers.

- Develop a one-stop service mechanism: Set up a one-stop service mechanism in health facilities with trained MR service providers; ensure adequate supply of MR medicines and logistics in facilities; make provisions for complication management and availability of referral facilities.

- Build capacity and resource utilization: Increase the number of field staff with adequate knowledge and training on MRM.

- Improve record-keeping systems: Establish a proper and improved reporting system to maintain register books for MRM service provision and documentation. 


\section{REFERENCES}

[1] Akhter HH. Abortion: A Situation Analysis. In: Akhter HH, Khan TF. A Bibliography on Menstrual regulation and Abortion Studies in Bangladesh. Dhaka Bangladesh Institute of Research for Promotion of Essential and Reproductive Health and Technologies 1996.

[2] Chowdhury SNM and Moni D, A situation analysis of the menstrual regulation programme in Bangladesh, Reproductive Health Matters, 2004, 12(24, Suppl.): 95-104.

[3] Johnston HB et al., Scaled up and marginalized: a review of Bangladesh's menstrual regulation programme and its impact, in: Blas E, Sommerfeld J and Kurup AS, eds., Social Determinants Approaches to Public Health: From Concept to Practice, Geneva: World Health Organization (WHO), 2011, pp. 9-24.

[4] Government of the People's Republic of Bangladesh. Directorate General of Family Planning: MCHServices Unit. Memorandum No.: DGFP/MCH-RH/pro-sha (admin) 23/05/108. 03 February 2015.

[5] Singh S et al., The incidence of menstrual regulation procedures and abortion in Bangladesh, 2010. International Perspectives on Sexual and Reproductive Health, 2012, 38(3):122-132.

[6] Strengthening the National Menstrual Regulation Programme for Reduction of Maternal Mortality and Morbidity in Bangladesh. 27 November - 11 December 2010

Dhaka, Bangladesh. Mid-Term Review Report. World Health Organization (WHO) 2011.

[7] Directorate General of Family Planning, Bangladesh National Menstrual Regulation Service Guidelines, 2014, Dhaka, Bangladesh: Directorate General of Family Planning and World Health Organization (WHO) Country Office for Bangladesh; and Amsterdam: Kingdom of the Netherlands, 2014.

[8] Government of the People's Republic of Bangladesh. Directorate General of Family Planning: MCHServices Unit. Memo No.: DGFP/MCH-S/NTC-4/138/95/ (part-05)/34. Proceeding of the $61^{\text {th }}$ meeting of National Technical Committee (NTC) held on 26th November, 2013.

[9] Personal communication, Dr. Farid Uddin Ahmed, Deputy Director, MCH-Services Unit, Directorate Generate of Family Planning, Dhaka, Bangladesh.

[10] Singh S et al., The incidence of menstrual regulation procedures and abortion in Bangladesh, 2014. International Perspectives on Sexual and Reproductive Health, 2017, 43(1): TK-TK, https://doi.org/10.1363/43e2417.

[11] Menstrual Regulation and Induced Abortion in Bangladesh. Fact Sheet. Guttmacher Institute.

September 2012. https://www.guttmacher.org/sites/default/files/factsheet/fb-bangladesh-mr.pdf Retrieved on 30 September 2017.

[12] Nanda P and Mishra A, Understanding the Determinants of Safe Abortion Services in Bangladesh: The Perspective of Users and Gate keepers, London: International Planned Parenthood Federation, 2011.

[13] MRM Working Group (MRM WG), Terms of Reference (ToR), Date: 27 March, 2012.

[14] Report on MR with Medication: Relevance, Issues, and Opportunities. Seminar and Roundtable. Hotel Sheraton, Dhaka. December 9, 2007. 
[15] Unsafe abortion after legalisation in Nepal: a cross-sectional study of women presenting to hospitals. Rocca CH, Puri M, Dulal B, Bajracharya L, Harper CC, Blum M, Henderson JT. BJOG. 2013 Aug; 120(9):107583. doi: 10.1111/1471-0528.12242. Epub 2013 Apr 10.

[16] Alam A, Bracken H, Johnston HB, Raghavan S, Islam N, Winikoff B, Reichenbach L. Acceptability and Feasibility of Mifepristone-Misoprostol for Menstrual Regulation in Bangladesh. International Perspectives on Sexual and Reproductive Health. 2013; Vol. 39, No 2. p. 79-87.

[17] "Dissemination Seminar: New Technologies for Menstrual Regulation: Experience in Bangladesh". Hotel Sarina, Banani, Dhaka, Bangladesh. 03 November, 2010.

[18] Government of the People's Republic of Bangladesh. Directorate General of Family Planning Maternal and Child Health Services Unit. Proceedings of $57^{\text {th }}$ the National Technical Committee meeting. 2011. Memo No: DGFP/MCH-S/NTC/-4/138/95 (Part 4)/74.

[19] Hena IA, Rob U, Sultana N, Hossain MI, Yasmin R, Das RT, Ahmed FU. 2013. "Introducing Medical Menstrual Regulation in Bangladesh: MRM Final Report." Dhaka, Bangladesh: Population Council.

[20] Alam A, Lotarevich T, Bracken H, Reichenbach L, Winikoff B. Introducing mifepristone- misoprostol for menstrual regulation in public sector facilities in Banglaesh. 3rd International Congress on Women's Health and unsafe Abortion (IWAC 2016), Jan 26-29, 2015, Bangkok, Thailand

[21] Shamsuddin L. Obstetrical and Gynaecological Society of Bangladesh (OGSB) (2013). Pilot Implementation of Medical Termination of Pregnancy (MTP) in Dhaka City using Medical Methods. Directorate General of Health Services (DGHS) and Directorate General of Family Planning (DGFP).

[22] Powell-Jackson T, Acharya R, Filippi V, Ronsmans C. 2015. Delivering medical abortion at scale: A study of the retail market for medical abortion in Madhya Pradesh, India. PLoS ONE 10(3):e0120637. doi:10.1371/journal.pone.0120637.

[23] Directorate General of Drug Administration. Ziska Pharmaceuticals Bangladesh. Mifepristone Drug Registration No: 242-254-85. License No. 424 OF. 13 September 2012.

[24] Directorate General of Drug Administration. Mife-Miso Drug Registration Memo. No: DA/LAB/CART/242/011/2559. 25 February 2013.

[25] Government of the People's Republic of Bangladesh. Directorate General of Family Planning: MCHServices Unit. Memo No.: DGFP/MCH-S/NTC-4/138/95/(part-05)/34. Proceeding of the $61^{\text {th }}$ meeting of National Technical Committee (NTC) held on 26 $6^{\text {th }}$ November, 2013.

[26] Bangladesh National Service Delivery Guideline on Menstrual Regulation with Medication (MRM). MCH-Services Unit, Directorate General of Family Planning, Ministry of Health and Family Welfare. September 2015. 


\section{LIST OF KEY INFORMANTS}

Groups

Key informants

Designation

\begin{tabular}{|c|c|c|c|}
\hline \multirow[t]{8}{*}{ Policy Makers } & 1 & Dr. Mohammad Sharif & Director, MCH, DGFP \\
\hline & 2 & Dr. S. M. Shahidullah & Country Director, Ipas Bangladesh \\
\hline & 3 & Dr. Sharif M I Hossain & Associate, Pop-Council Bangladesh \\
\hline & 4 & Maj. Gen. Md. Jahangir H Mollik & Ex-DG (DGDA) \\
\hline & 5 & Prof. LatifaShamsuddin & Ex-president (OGSB) \\
\hline & 6 & Prof. Saleha Begum & Chairman (ObsGynae) BSMMU \\
\hline & 7 & Dr. TapashRanjan Das & $\mathrm{DD}$ and $\mathrm{PM}, \mathrm{MCH}-\mathrm{DGFP}$ \\
\hline & 8 & Dr. Reena Yasmin & Marie Stopes \\
\hline \multirow[t]{9}{*}{ Implementers } & 9 & Dr. Altaf Hossain & Director, BAPSA \\
\hline & 10 & Dr. QuaziSuraiya Sultana & Executive Director, RHSTEP \\
\hline & 11 & Dr. Jashim Uddin & DDFP - Patuakhli \\
\hline & 12 & Dr. Afroza & MO - MCWC \\
\hline & 13 & Fatema Yasmin & FWV - (MCWC) Patukhali \\
\hline & 14 & TanjinaMukta & FWV - (Bodorpur) Patukhali \\
\hline & 15 & Dr. Ulfat Ara & MO - Marie Stopes Clinic, Elephant road \\
\hline & 16 & Dr. Lutfa Rahman & MO - RHSTEP, DMCH \\
\hline & 17 & Dr. Nighat Rahman & MO - BAPSA \\
\hline \multirow{2}{*}{$\begin{array}{l}\text { Pharmaceutical } \\
\text { Companies }\end{array}$} & 18 & Dr. Sayeed Ahmed & Head - MSD, Ziska Pharma Ltd \\
\hline & 19 & Mizanur Rahman & Manager - MSD, Incepta Pharma Ltd \\
\hline \multirow[t]{8}{*}{ Medicine Sellers } & 20 & Mr. Sanjoy & Aontee Pharmacy, Borobag, Mirpur-10 \\
\hline & 21 & Mr. Asaduzzaman & Tamanna Pharmacy, Mirpur-10 \\
\hline & 22 & Abu Taleb & Shahjalal Pharmacy, Koylaghat, Sylhet \\
\hline & 23 & Mujibor Rahman & Padma Pharmacy, Uposhohor, Sylhet \\
\hline & 24 & Debobroto Pal & Sunil Drug, Uposhohor, Sylhet \\
\hline & 25 & Md. Abul Bashar & Potuakhali \\
\hline & 26 & Mr. Anwar & Gazipur \\
\hline & 27 & Mr. Mobarak & Gazipur \\
\hline \multicolumn{4}{|c|}{ Mention about Three Mystery client } \\
\hline
\end{tabular}




\section{PHOTO GALLERY}

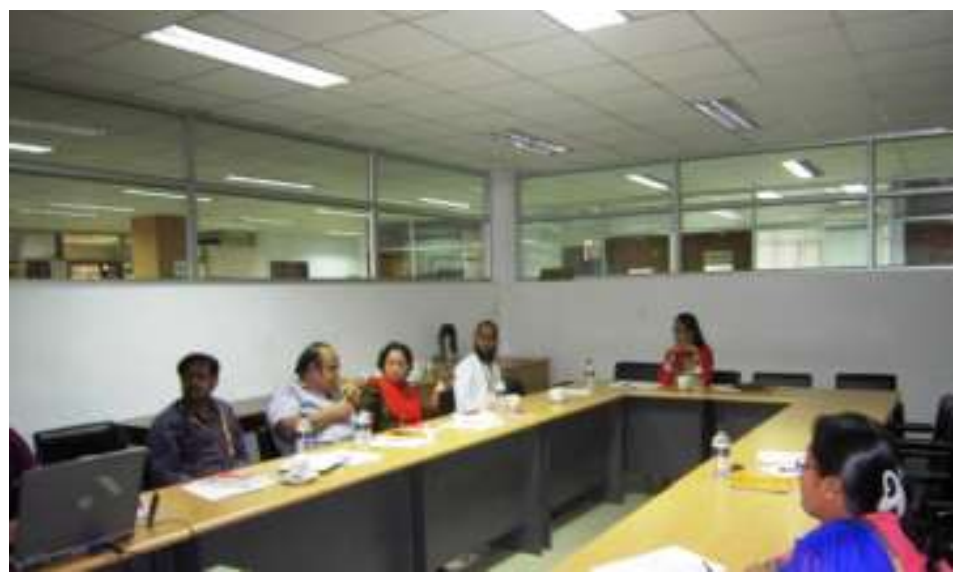

MRM Study Team Meeting

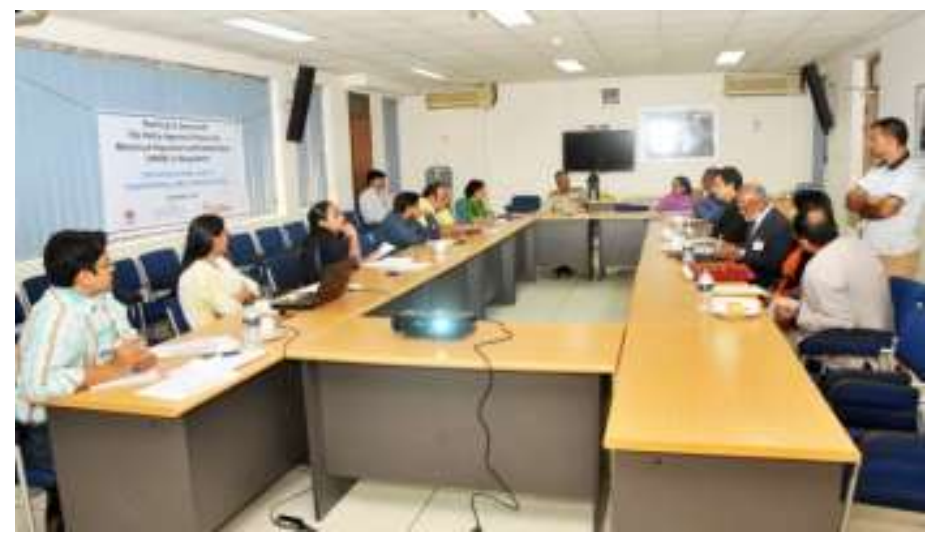

MRM Round Table Meeting With Key Informants

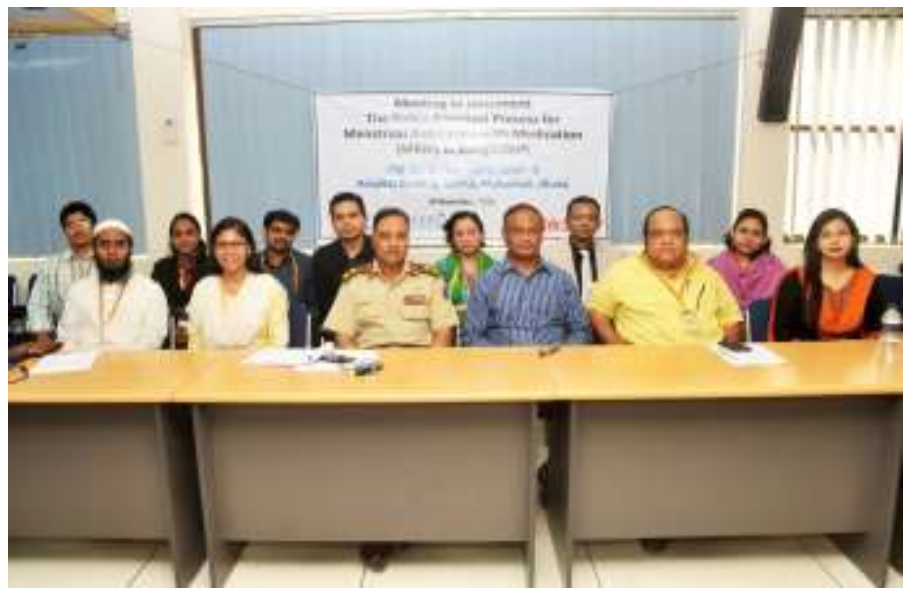

MRM Round Table Meeting With Key Informants 